\title{
La cordillera de los Andes no es frontera. Cuerpos-territorios y medicina ancestral mapuche en contexto de pandemia
}

\author{
Daiana Melón* y Florencia Yanniello**
}

Resumen: El artículo analiza la campaña La Cordillera no es Frontera, impulsada por el Movimiento de Mujeres Indígenas por el Buen Vivir ante la situación de la machi (autoridad mapuche en salud) Mawün Jones, de Ngulumapu (actual territorio chileno), quien cruzó la cordillera de los Andes para atender pacientes en Puelmapu (actual territorio argentino), y quedó varada por las medidas de aislamiento decretadas por la pandemia del COVID-19. La campaña promovió el regreso de la machi a su territorio y también un debate sobre los límites políticos que impusieron los Estados argentino y chileno en el territorio mapuche y las lógicas de control social sobre las mujeres indígenas. Proponemos reflexionar sobre la cordillera como frontera política, geográfica, simbólica y corporal. Esto implica revisar las decisiones de los Estados que afectan a las personas que atraviesan desigualdades étnicas y de género, y que además practican formas de medicina no reconocidas.

Palabras clave: pueblo mapuche, mujeres indígenas, cuerpo-territorio, medicina ancestral, fronteras
Abstract: The article analyzes the campaign «La Cordillera No Es Frontera», promoted by the Indigenous Women's Movement for Good Living due to the situation of the machi (Mapuche health authority) Mawün Jones, from Ngulumapu (current Chilean territory), who crossed the Andes Mountain range to assist patients in Puelmapu (current Argentinian territory), and was stranded due to the isolation measures decreed because of the COVID-19 pandemic. This campaign fostered the machi's return to her territory and also a debate on the political limits imposed by the Argentine and Chilean States on Mapuche territory and the logic of social control over indigenous women. We propose to reflect on the mountain chain as a political border, as well as a geographical, symbolic, and physical border. This implies reviewing the decisions of the States that affect people who experience ethnic and gender inequalities, and who also practice unrecognized forms of medicine.

Keywords: Mapuche people, indigenous women, body-territory, ancestral medicine, borders

\footnotetext{
* Centro de Investigaciones Geográficas. Instituto de Investigaciones en Humanidades y Ciencias Sociales, IdIHCS/Conicet. Colectivo Tinta Verde. E-mail: daianamelon@gmail.com.

** Instituto de Investigaciones en Diversidad Cultural y Procesos del Cambio, UNRN-Conicet. Colectivo Tinta Verde. E-mail: florenciayanniello@gmail.com.
} 


\section{Introducción}

El pueblo mapuche constituye una unidad política, lingüística y cultural que se sitúa a ambos lados de la cordillera de los Andes y del centro al sur de las actuales repúblicas de Argentina y Chile. Al igual que otros pueblos originarios, la situación de las comunidades mapuche ${ }^{1}$ fue marcada por los genocidios: la "conquista del desierto" y la "pacificación de la Araucanía», llevadas adelante por los Gobiernos argentino y chileno, respectivamente, en la segunda mitad del siglo XIX (Yanniello, 2020).

En la actualidad, este pueblo sigue asentado en Wallmapu (territorio mapuche), que incluye Puelmapu (zona del este, actualmente Argentina) y Ngulumapu (zona del oeste, hoy Chile). Es por eso por lo que para las comunidades - que siguen luchando por reivindicar su identidad como nación preexistente- la cordillera de los Andes, división política establecida por estos dos países, no representa más que una frontera impuesta que limita su pleno desarrollo.

Esta situación se vio profundizada por la pandemia del COVID-19 y las medidas que impulsaron ambos países, que implicaron restricciones en torno al funcionamiento de ciertas instituciones, la movilidad de las personas, controles oficiales y cierre de fronteras. Las comunidades mapuche experimentaron una preocupación particular por la limitación de la circulación, que impidió el traslado del lawen (medicina ancestral) y la realización de ceremonias fundamentales para la salud y el kvmefelen (bienestar) de las comunidades (Tomas y Santisteban, 2020). En este marco, desarrollaremos el caso de la machi Mawün Jones, que sintetiza numerosos conflictos y dificultades cotidianas del pueblo mapuche.

1. Utilizamos el término mapuche, incluso para referirnos en plural, ya que el significado de esa palabra es "gente de la tierra» y en la lengua originaria de este pueblo no existe la palabra mapuches.

\section{El origen de la campaña}

La machi Mawün Jones llegó el 14 de marzo a Esquel, Argentina, desde su comunidad, Juan Huentelen, en las afueras de Temuco, Chile. Una semana después, el presidente argentino, Alberto Fernández, decretó el aislamiento social preventivo y obligatorio por la pandemia del COVID-19. En este contexto, la machi quedó varada durante más de seis meses sin poder regresar. A raíz de esta situación surgió la campaña La Cordillera no es Frontera - Chi Mawiza Malal Femngelay. Por el Retorno Inmediato de la Machi Mawün a su Rewe [lugar ceremonial], impulsada por el Movimiento de Mujeres Indígenas por el Buen Vivir.

Este movimiento está compuesto por mujeres de treinta y seis naciones originarias que viven en la actual Argentina, y viene visibilizando distintas problemáticas que atraviesan en su condición de mujeres e indígenas. Tal como señala el Colectivo Miradas Críticas del Territorio desde el Feminismo (2017), el cuerpo es el primer territorio y al territorio lo reconocemos en nuestros cuerpos. Entendemos que el cuerpo de las mujeres e identidades feminizadas es el lugar en el que persisten las estructuras institucionales e institucionalizadas, donde se plasman las políticas de jerarquización y estructuras de poder, es decir, se trata del «ensamblaje corporalizado de género, raza, clase, sexualidad y edad» (Marchese, 2019: 12).

En este marco, comprendemos las identidades múltiples de las mujeres que conforman este movimiento, que en abril de 2020 impulsó la campaña con el objetivo de mostrar — a través de videos cortos - los fundamentos espirituales y territoriales de la medicina mapuche. «La machi había estado tramitando a través del Instituto Nacional de Asuntos Indígenas [de Argentina] un permiso que nunca llegó y estuvo golpeando puertas que nunca se abrieron", explica Moira Millán, weichafe (luchadora) mapuche e impulsora del movimiento. Millán cuenta que la campańa sintetizó una situación cotidiana para el pueblo mapuche con respecto al tránsito de 
un lado al otro de la cordillera y la dificultad de transportar el lawen, la medicina ancestral mapuche compuesta por hierbas y elementos de la naturaleza, que las aduanas no dejan pasar por no tener aprobación de los organismos sanitarios. "Nos parecía oportuno ejemplificar el derecho de la machi a volver, como el derecho de nuestro pueblo a liberar la medicina mapuche», agrega.

Por su parte, Rosa Catrileo, abogada, integrante de la Comunidad de Historia Mapuche y organizadora de la campaña, señala:

La machi pertenece al pueblo mapuche, que es transfronterizo. De acuerdo a nuestra visión, y a lo que como abogada denomino «derecho propio», ella estaba dentro de nuestro territorio, es una ciudadana mapuche y debería haber protocolos especiales para garantizar su paso a ambos lados de la cordillera.

\section{Las múltiples fronteras}

Mezzadra y Neilson (2017) sostienen que las fronteras no son meramente bordes territoriales o geográficos, sino que son instituciones sociales complejas marcadas por tensiones entre prácticas de reforzamiento y atravesamiento; constituyen dispositivos de inclusión y exclusión y poseen capacidad de jerarquización y estratificación. Según su planteamiento, existen distintos tipos de fronteras que desempeñan funciones de demarcación y territorialización, y las personas pertenecientes a diferentes grupos sociales las experimentan de diversas formas. En este marco, la violencia modela las vidas y las relaciones que se despliegan en y a través de las fronteras, por lo que son espacios de lucha.

Desde este ángulo, tal como señala Moira Millán, para el pueblo mapuche «la frontera entre Argentina y Chile es artificial, es una frontera impuesta para cortar en dos mitades Wallmapu». $\mathrm{Y}$ agrega:
Tenemos Puelmapu bajo invasión argentina y Ngulumapu bajo invasión chilena. En ambos casos lo que se busca es debilitar al pueblo mapuche y nuestros derechos para transitar nuestro territorio. Esto genera muchos problemas, sobre todo en la búsqueda de la salud, en el fortalecimiento espiritual e identitario.

Maffía (2009) analiza la dimensión simbólica de la frontera como un sistema de identidad de características normativas, y plantea que esta reordena dimensiones de la vida. Para esta autora, existen cuerpos sometidos por la cultura dominante, en los cuales se configuran relaciones de poder, de dominio y de opresión.

En esta línea se orientan las palabras de Millán: «La frontera se convierte en una línea divisoria no solamente entre los Estados nación, sino entre la hegemonía blanca y la diversidad de los pueblos indígenas». Moira hace hincapié en que el límite entre Argentina y Chile «es una división entre el mundo occidental y el mundo mapuche», y plantea:

Se utiliza la frontera como un espacio de represión, de cercenamiento de derechos, se secuestra el lawen cuando pasamos de un lado al otro y muchas veces los pacientes dependen de esa medicina porque se están tratando y la deben pasar de manera clandestina. Es una situación completamente represiva.

\section{Las fronteras sobre la salud y los cuerpos}

Con la pandemia, el discurso político se enmarcó en la autoridad de la medicina y la biología para gestionar los riesgos, y se tomaron medidas de alto impacto preventivo en la población, que las comunidades mapuche cuestionaron en tanto consideraron que se trataba de criterios monolingües de la «autoridad sanitaria» (Ramos y Yanniello, 2021) basados en un único paradigma de salud. 
Así, la campaña tuvo como objetivo demandar la implementación de medidas acordes a las prácticas de la medicina mapuche y los principios de sus conocimientos en salud. Esto puso de relieve también el reclamo de que se contemplen la importancia del territorio y el resguardo de sus fuerzas constitutivas, imprescindibles para tener kvmefelen, es decir, salud y bienestar (Tomas y Santisteban, 2020). Desde la perspectiva mapuche, la pandemia evidenció que las soluciones brindadas por la salud occidental tienden a ser cortoplacistas, ligadas únicamente a la amenaza del virus (Ramos y Yanniello, 2021).

Sobre este tema, Rosa Catrileo señala: «Comenzamos a dar cuenta de que nuestras machis no pueden transitar por la frontera y de los problemas preexistentes respecto del lawen, porque muchas veces es retenido en las aduanas o no dejan pasarlo de una frontera a otra, arguyendo temas fitozoosanitarios».

El problema del lawen representa la yuxtaposición de las fronteras políticas, geográficas, simbólicas y culturales entre el pueblo mapuche y los Estados argentino y chileno, ya que la línea fronteriza que los divide genera una serie de limitaciones al desarrollo pleno de este pueblo, que incluye una mirada occidental que no contempla el concepto integral de salud o bienestar mapuche. En ese sentido, Millán explica: «Las machis son personas que tienen las características espirituales para albergar las fuerzas de la tierra que les traen conocimiento medicinal». Por su parte, Roxana Miranda Rupailaf, poeta mapuche, profesora de Lengua Castellana y Comunicación de la Universidad de Los Lagos y colaboradora de la campańa, explica que tratarse con una machi «tiene que ver tanto con una sanación espiritual como con lo corporal, se ve la salud como un todo». Además, señala que existen restricciones y desconfianza en los cruces fronterizos: «Hay mucha discriminación respecto al paso de las machis por las aduanas y de la gente mapuche en general, por nuestro aspecto y vestimenta. Es muy complejo ir y venir y transportar el lawen».

\section{Conclusión}

El caso analizado condensa un complejo entramado de conflictos entre el pueblo mapuche y los Estados argentino y chileno que la pandemia agudizó. Se trata de una situación que pone en evidencia cómo la invasión a los pueblos originarios sigue operando cotidianamente sobre las lógicas y el desarrollo pleno de las comunidades, de maneras más sutiles y —a veces- menos violentas.

Siguiendo la definición de frontera simbólica de Maffía (2009), encontramos que el caso de la machi Mawün representa las distintas fronteras que atraviesan a las mujeres indígenas, que además practican un tipo de medicina no reconocida por los Estados. En ese sentido, vemos cómo se articulan desigualdades étnicas y de género en personas condicionadas por una legalidad que les resulta ajena, que les impide circular libremente por su territorio, practicar la medicina ancestral y transportar el lawen. Este control sobre los cuerpos-territorios se impone mediante fronteras físicas, legales, políticas y culturales, que dejan por fuera cualquier tipo de interpretación desde la cosmovisión mapuche.

El Movimiento de Mujeres Indígenas por el Buen Vivir representa un espacio de resistencia a esas fronteras impuestas sobre los cuerpos, los territorios y la salud, y esta campaña, impulsada por mujeres de ambos lados de la cordillera, demuestra que la fuerza de la tierra y de las mujeres es más imponente que la de cualquier límite político que se haya definido por decretos, guerras o acuerdos binacionales. 